\section{A Gift}

The German Physical Society completing the hospitable welcome we had received from our hosts in Berlin-West, offered to EPS without charge the computer with its soft-ware that they had been using but had now out-grown. Council warmly applauded this gesture and a study will be made of its suitability to see if in the near future the main
Secretariat as well as the Supplementary Secretariat in Budapest can be equipped with modern devices.

\section{Next Meeting}

The next meeting of Council will be held in London following the Seminar on International Research Facilities which will be held from 17 March p.m. to 19 March 1986, mid-day.

\title{
5th CMD General Conference
}

Orchestrated with discrete efficiency, the 5th EPS General Condensed Matter Conference took place in Berlin-West 18-22 March - not as foreseen in the new Physics Department of the Technical University, finished ahead of schedule in order to be available - but in the University's conference building because the number of registrations had become so large. The Condensed Matter Division has been gratified in the past by the number of participants at its general conferences but this was something different: 1550 registrations, over 1000 submitted papers; five days of poster sessions with 190 posters/day which drew an average attendance of over 1000.

The very big numbers were in large measure the result of the Conference being joined to the traditional March Physikertagung of the German Physical Society. Of the participants, over 900 wore badges indicating they were from the Federal Republic of Germany but many of the faces betrayed a provenance from much further away. This was evident in the list of authors which included contributors from almost the whole world and many of the papers were the consequence of joint activities with people even as far afield as China. At a rough estimate only about two thirds of those with an FRG badge were permanent residents of the country. Such is the pattern of research in the universities today in the FRG. There is a steady flux of people from abroad, maintaining a foreign population among researchers of about $20 \%$ - a population at its most inventive and productive age.

The popularity of the Physikertagung merits some reflexion. Undoubtedly over a number of years, research in the FRG has been well endowed, not least in condensed matter, and the membership of the DPG has grown impressively 8100 in 1984, 9100 in 1985 already, but the tradition is deeper than that. Most of those attending make the trip at their own expense - as a necessary part of their career activity and the organizers encourage this by keeping the registration fees low (100-120 DM on this occasion, and students in effect free, not to mention a generous number of guests from abroad) and having available good simple accommodation (30 DM the night). Another feature is the care taken over the plenary lectures, a feature emulated this year by the International Programme Committee. Presentations were, with but one or two exceptions, of real didactic value - up to the moment, but with adequate background to give ready understanding. The arch demonstration of this was perhaps the very last lecture by H.O. Peitgen of Bremen on the somewhat forbidding subject of Phase Transitions and Complex Dynamical Systems as seen by a mathematician. What followed was an elegant introduction to the obscure Julia sets, leading on to the conception of non-integral dimensional systems and fractals. These were then illustrated through a flashing panorama of computer graphics which showed the same "sea-horse" pattern reappearing again and again as the scale was increased by orders upon orders of magnitude, to the evident delight of a packed audience whose final applause was in appreciation as much of the manner as of the substance of the talk. Again on the question of presentation one could note the generally high quality of the posters. No longer did one find boards covered with scruffy photostat copies in characters so small and inaccessible that the bifocal wearer found them impossible to read through either lens. Bold, clear and explicit was the formula of the day.

As the Chairman of the Condensed Matter Division reminded the participants, European physicists working in condensed matter used to meet at the March meeting of the APS; now they could meet in Europe. And as if to confirm the emancipation, we were also treated to a beautifully balanced talk given by the retiring President of the APS, Mildred Dresselhaus on Layered Crystals and Intercalated Compounds, following which she fielded with practised ease a question thrown at her on American defence policy because she dared in her introductory remarks to speak of a golden age in physics. Who looking round the packed halls or mixing with the chattering throng could doubt her contention?

It is never easy at such big conferences to identify the key subjects but readers can judge for themselves either by consulting Europhysics Conference Abstracts Vol. 9A, or the proceedings to be published in Advances in Solid State Physics (promised in three months!). Three topics however, caught the attention and will be reviewed later in Europhysics News, namely heavy fermions, the pervasiveness of tunnelling now in condensed matter measurement and the importance of applied physics in the field (see opposite).

It was noticeable that roughly half the posters were on semiconductors and the symposium on devices attracted a very large following. So too did the symposium on the quantum Hall effect. Far from this being an exhausted subject, the ramifications of the integral and fractional effects seem to be steadily widening. Turbulence, chaos and non-linear dynamics was another symposium with a large following and it is clear that this is a field of growing significance - not just in physics but right across the sciences including the live sciences, the social sciences and economics.

Too easily can it be said that the host city reserved a warm welcome to the conference - exemplified by the greeting by the Chairman of the Senate and the subsequent reception in the restored Schloss Charlottenburg - but it would be difficult to have a more convincing proof of the good-will shown than that of allowing the Conference Programme Committee to choose the programme at the famous Deutsche Oper. (That hardly sounds like two cultures!) Altogether, it was an enormously successful meeting to start off the EPS season, and the organizers led by J. Treusch as Conference Chairman, with $\mathrm{N}$. Nelkowski and D.H. Haberland as Chairman and Secretary of the Organizing Committee (plus wives) and M. Cardona, Chairman of the Programme Committee fully merited the applause they received. 